\title{
Bee sting of the cornea: A running case report
}

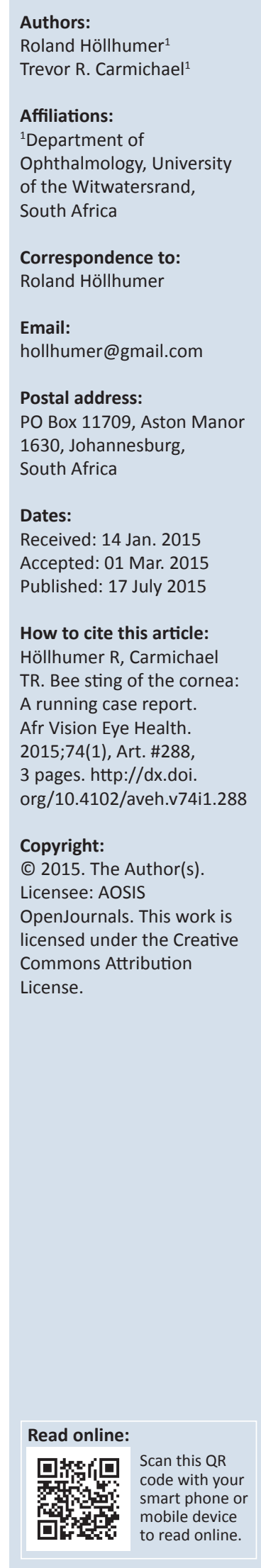

Bee stings that present with ocular sequelae are infrequently reported in the literature. The present report is of a retained corneal bee stinger with a delayed presentation. A review of case reports reveals a number of potential ocular complications of bee stings. The ocular sequelae and treatment options are reviewed.

\section{Introduction}

Bee stings that present with ocular sequelae are infrequently reported in the literature. A review of case reports reveals a number of potential ocular complications of bee stings. The present report is of a retained corneal bee stinger with a delayed presentation.

\section{Case report}

A 5-year-old girl presented to the Ophthalmology Department at Charlotte Maxeke Johannesburg Academic Hospital with a month-long history of a mild irritation in the left eye. Further enquiry revealed an admission to hospital a month before, after she was attacked by a swarm of bees. At that time, she was admitted to the ICU for observation, but no mention was made of an ophthalmological complaint. On examination, she had a best corrected visual acuity of $6 / 6$ in the right and $6 / 18$ in the left eye. The examination of the right eye was unremarkable. She had injection of the conjunctiva inferiorly in the left eye with an associated inflammatory limbal nodule, but no mucopurulent discharge was noted (Figure 1). She had an embedded stinger in the left cornea with the tip exposed through the epithelial surface adjacent to the limbal nodule. Her anterior segments were quiet, lenses clear and posterior segments normal. She had no evidence of optic nerve swelling or dysfunction. She was taken to theatre for removal of the stinger. A linear incision was made over the stinger from apex to base and the stinger removed. Incising over the stinger in this fashion allowed complete removal without leaving any fragments behind. Owing to the depth of the stinger, a single 10.0 nylon suture was inserted to maintain corneal integrity (Figure 2). The patient was managed postoperatively with a topical steroid solution and antibiotic ointment. The suture was removed 2 weeks later under slit lamp examination. The patient developed a scar at the site and had best corrected vision of $6 / 9$ at her last documented follow-up 2 weeks postoperatively (Figure 3).

\section{Discussion}

Bee stings to the head region are associated with a number of ocular sequelae that may be caused by the mechanical effect of the stinger itself or the embedded venom. Many of these cases have been described from as far back as 1931; the most common is a mucopurulent keratoconjunctivitis with corneal infiltrates. Other features of anterior segment involvement include iritis, hyphaema, lens opacification, lens subluxation, mydriasis and internal ophthalmoplegia. The posterior segment is rarely involved, but cases of optic neuritis followed by optic atrophy have been described. ${ }^{1,2,3}$

The stinger of a bee has a unique multi-barbed anatomy that results in it remaining embedded at the site of a sting. The venom of the stinger ranges in volume from $50 \mu \mathrm{g}$ to $300 \mu \mathrm{g}$, which may account for the variable response to a bee sting. The venom has both a toxic and allergenic potential. There are a number of well-described components to bee venom; however, an increasing number of new components have been described in new research. Phospholipase A2 and hyaluronidase are the two most important antigens responsible for the allergenic reaction. Melittin contributes most to the volume of the bee venom and is responsible for the pain and inflammation following a bee sting, which is attributed to the lysis of erythrocytes, leukocytes and myocytes that is caused by the melittin. ${ }^{4}$ Apamin makes up $2 \%$ of the bee venom and is thought to be the neurotoxin responsible for internal ophthalmoplegia and optic neuritis. ${ }^{5}$ 


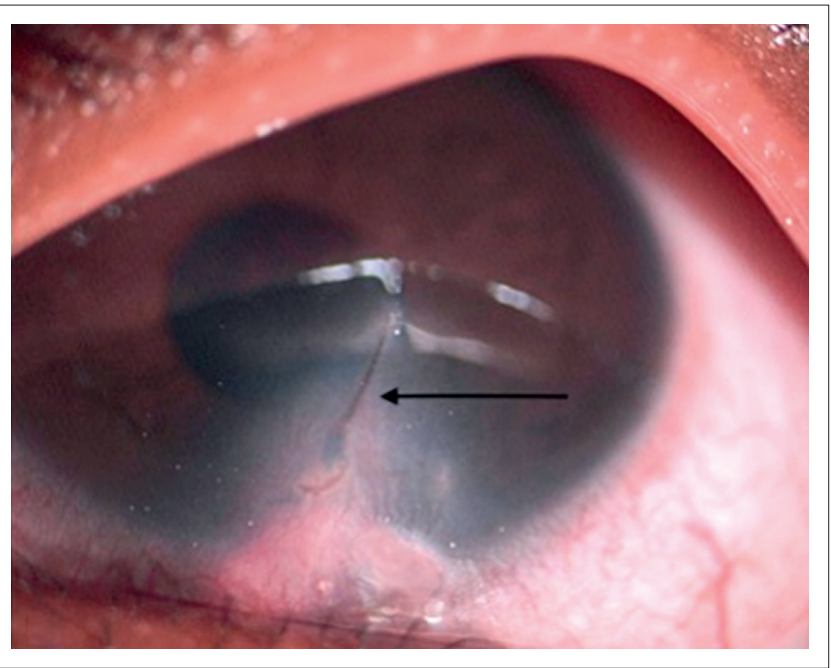

Source: Photo taken by Professor Trevor Carmichael

FIGURE 1: Retained bee stinger in the cornea (black arrow) with adjacent inflammatory limbal nodule and conjunctival inflammation.

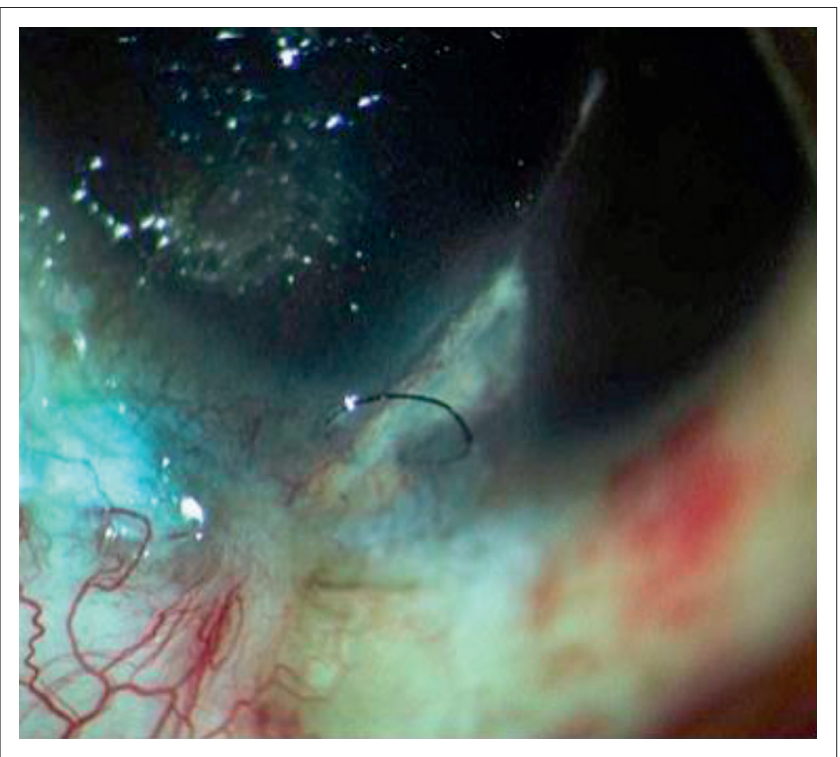

Source: Photo taken by Professor Trevor Carmichael

FIGURE 2: One week after operation, with a suture in place. Note that inflammation has decreased with early stromal vascularisation.

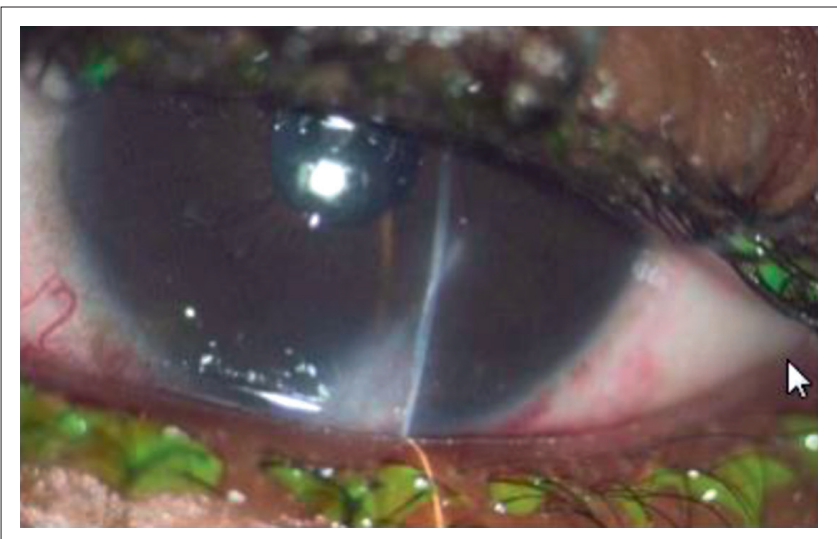

Source: Photo taken by Professor Trevor Carmichael

FIGURE 3: Two weeks post operation. Note that suture has been removed. Scarring and deep stromal vascularisation can be appreciated.
A sting to the cornea will produce mechanical and toxic damage. The toxins produce an immediate effect that presents with corneal oedema, striate keratopathy and corneal infiltrate around the stinger. The corneal findings may be accompanied by an anterior uveitis..$^{5,6}$ Once the effect of the toxin wears off, the presence of the stinger is well tolerated. This was confirmed by Strobel in 1931, ${ }^{6}$ where rabbit studies showed the presence of a retained corneal stinger to be inert. A case report by Gilboa et al. ${ }^{6}$ presented a stinger retained in the anterior capsule of the lens, with no inflammatory sequelae over 28 years of follow-up. The lens may develop anterior subcapsular opacities or an anterior polar cataract with time. ${ }^{6}$ A report by Gürlü et al. ${ }^{7}$ showed a decrease in endothelial cell density and polymorphism, which is thought to be caused by the bee venom itself. In wasp stings, this is a more severe reaction that usually results in a bullous keratopathy. ${ }^{7}$ The literature reports one case of a retained stinger in the tarsal plate. The patient presented with ocular discomfort and a red eye after being stung by a bee. Examination revealed corneal stromal oedema and extensive linear epithelial abrasions. Further examination revealed a retained stinger in the tarsal plate. ${ }^{8}$ The literature frequently reports hyphaema and lens subluxation as complications of a bee sting, although these were not noted in any of the case reports reviewed for the present article.

Blepharochalasis is a condition characterised by recurrent lid oedema that results in thin, loose and therefore redundant skin of the lids. Although both lids may be involved, it is more common in the upper lid. The literature reports one case of blepharochalasis that developed in a 14-year-old girl after being stung by a bee. She suffered repeated bouts of lid oedema after the sting that resulted in redundant upper lid skin obstructing her visual axis. She had a bilateral blepharoplasty done which relieved her symptoms. ${ }^{9}$

Posterior segment sequelae after a bee sting is rare; the most common of these is an optic neuritis. There is one report in the literature of a ciliochoroidal detachment developing within hours after a bee sting to the cornea. The patient responded well to oral prednisone therapy and recovered $6 / 6$ vision. ${ }^{10}$

Optic neuritis following bee stings to the head area have rarely been described, with the first reported by Goldstein et al. ${ }^{6}$ in 1960. Most reports of optic neuritis present within hours of the bee sting, with a marked decrease in visual acuity, colour perception and contrast sensitivity. The neuritis may present as a papilitis or a retrobulbar optic neuritis. Song et al. ${ }^{1}$ reported on a 38-year-old man who developed a unilateral optic neuritis after a bee sting; serial visual evoked potentials (VEP) and electroretinograms (ERG) was performed on him. The initial pattern VEP showed prolonged latency of the P100 wave, with a complete block of the optic nerve conduction on the VEP 2 years later. The pattern ERG was normal on all occasions, indicating the health of the photoreceptors and Müller cells. From these findings, it was hypothesised that bee venom causes a demyelinating optic neuritis with subsequent degeneration of the axons to produce complete nerve block. ${ }^{1}$ Steroid therapy for the optic neuritis has been implemented 
in most reported cases, with variable outcomes. Choi et al. ${ }^{2}$ reported a patient with optic neuritis who recovered fully after starting intravenous methylprednisolone on the day of the bee sting. They gave intravenous methylprednisolone ( $250 \mathrm{mg}$ every 6 hours) for 3 days, followed by a week of oral prednisolone at a dose of $1 \mathrm{mg}$ per $\mathrm{kg}$. From this case, they suggested that early initiation of steroid treatment is likely to improve the chances of recovery from bee venominduced optic neuritis. ${ }^{2}$ Dysfunction of other cranial nerves has been described in case reports. $\operatorname{Lin}^{5}$ reported a patient with decreased sensation in the trigeminal distribution after a bee sting.

Management of a retained corneal bee stinger needs to be determined on an individual case basis. It can be managed surgically, medically or both. The removal of a retained stinger can be done at the slit lamp if superficially embedded or in theatre under an operating microscope. ${ }^{11}$ Owing to the multi-barbed anatomy of the stinger, small pieces may remain behind. This was shown by Krishnakumar et al. ${ }^{12}$ where confocal scanning laser ophthalmoscopy was done to rule out any retained stinger material. They found tiny fragments in situ that were not visible on slit lamp examination. As mentioned above, the stinger itself is inert and therefore the presence of residual stinger fragments is unlikely to be of any clinical significance. However, if there is evidence of persistent inflammation, the stinger or any piece of it will need to be removed; this was illustrated by Jain et al. ${ }^{13}$ who managed a patient with a chronic oedematous cornea and progressive scarring 2 years after a bee sting injury. The patient was initially managed as a viral keratitis, but on closer inspection the stinger was visible and the relevant history was obtained from the patient. After removal of the stinger, the oedema and inflammation resolved. There is no consensus in the literature on an ideal surgical approach to be used. The second component of management hinges on suppressing the inflammation caused by the bee venom. Anterior segment inflammation is managed with topical steroids and a cycloplegic as needed. A topical antibiotic is often added owing to the potential risk of infection at the site of penetration. Topical antihistamines may also offer symptomatic relief. ${ }^{14}$ Posterior segment inflammation mostly manifests as an optic neuritis which seems to respond to intravenous and oral steroids. Choi et al. ${ }^{2}$ suggest that starting treatment early improves the prognosis for visual recovery. The single case of ciliochoroidal detachment reported in the literature, responded well to an oral steroid. ${ }^{10}$

\section{Conclusion}

Bee stings that present with ocular sequelae are infrequently reported in the literature. They may manifest with both anterior and posterior segment complications. Several case reports have aided in our insight into these cases; nevertheless, management needs to be determined on an individual case basis.

\section{Acknowledgements Competing interests}

The authors declare that they have no financial or personal relationships which may have inappropriately influenced them in writing this article.

\section{Authors' contributions}

R.H. (University of the Witwatersrand) reviewed the literature and wrote the article. T.R.C. (University of the Witwatersrand) reviewed the article, did the surgery and took the 3 pictures.

\section{References}

1. Song HS, Wray SH. Bee sting optic neuritis: A case report with visual evoked potentials. J Clin Neuroophthalmol. 1991;11:45-49.

2. Choi MY, Cho SH. Optic neuritis after bee sting. Korean J Ophthalmol. 2000;14:4952. http://dx.doi.org/10.3341/kjo.2000.14.1.49

3. Arcieri ES, França ET, De Oliveria HB, Ferreira L, Gerreira MA, Rocha FJ. Ocular lesions arising after stings by hymenopteran insects. Cornea. 2002;21:328-330. http://dx.doi.org/10.1097/00003226-200204000-00019

4. Brown TC. Reactions to honeybee stings: Allergic prospective. Curr Opin Allergy Clin Immunol. 2013;13:365-371. http://dx.doi.org/10.1097/ACl.0b013e3283625144

5. Lin PH, Wang NK, Hwang YS, Ma DHK, Yeh LK. Bee sting of the cornea and conjunctiva management and outcomes. Cornea. 2011;30:392-394. http:// dx.doi.org/10.1097/ICO.0b013e3181f234a6

6. Gilboa M, Gdal-On M, Zonis S. Bee and wasp stings of the eye. Retained intralenticular wasp sting: A case report. Br J Ophthalmol. 1977;61:662-664. http://dx.doi.org/10.1136/bjo.61.10.662

7. Gürlü VP, Erda N. Corneal bee sting-induced endothelial changes. Cornea. 2006;25:981-983. http://dx.doi.org/10.1097/01.ico.0000226364.57172.72

8. Chaurasia S, Muralidhar R. Retained bee stinger in the tarsal plate. Int Ophthalmol. 2011;31:111-112. http://dx.doi.org/10.1007/s10792-011-9418-z

9. Finney JL, Peterson HD. Blepharochalasis after a bee sting. Plast Reconstr Surg 1984;73:830-832. http://dx.doi.org/10.1097/00006534-198405000-00021

10. Pal A, Azad RV, Sharma YR, Singh DV Davda MD. Bee sting-induced ciliochoroidal detachment. Eye. 2005;19:1025-1026. http://dx.doi.org/10.1038/sj.eye.6701720

11. Razmjoo H, Abtahi MA, Mohammadi Z, Abtahi SH. Management of corneal bee sting. Clin Ophthalmol. 2011;5:1697-1700.

12. Yuen KSC, Lai JSM, Law RWK, Lam DSC. Confocal microscopy in bee sting corneal injury. Eye. 2003;17: 845-847. http://dx.doi.org/10.1038/sj.eye.6700425

13. Jain V, Shome D, Nataranjan S. Corneal bee sting misdiagnosed as viral keratitis. Cornea. 2007;26:1277-1278. http://dx.doi.org/10.1097/ICO.0b013e31814b8bae

14. Smith DG, Roberge RJ. Corneal bee sting with retained stinger. J Emerg Med. 2001;20:125-128. http://dx.doi.org/10.1016/S0736-4679(00)00298-5 